\title{
Estimating probability of insemination success using milk progesterone measurements
}

\author{
P. Blavy, ${ }^{* 1}$ N. C. Friggens, ${ }^{*}$ K. R. Nielsen, $†$ J. M. Christensen, $\dagger$ and M. Derks $¥ \S \#$ \\ *UMR Modélisation Systémique Appliquée aux Ruminants, INRA, AgroParisTech, Université Paris-Saclay, 75005 Paris, France \\ †Lattec I/S, Slangerupgade 6, DK-3400 Hillerød, Denmark \\ łInstitut National de la Recherche Agronomique, Unité Mixte de Recherche 1213 Herbivores, F-63122 Saint-Genès Champanelle, France \\ §VetAgro Sup, BP 10448, Clermont Université, F-63000 Clermont-Ferrand, France \\ \#VetAgro Sup, Unité Mixte de Recherche 1213 Herbivores, Université de Lyon, F-69280 Marcy l'Etoile, France
}

\begin{abstract}
The aim of this study was to quantify the effects of progesterone profile features and other cow-level factors on insemination success to provide a real-time predictor equation of probability of insemination success. Progesterone profiles from 26 dairy herds were analyzed and the effects of profile features (progesterone slope, cycle length, and cycle height) and cow traits (milk yield, parity, insemination during the previous estrus) on likelihood of artificial insemination success were estimated. The equation was fitted on a training data set containing data from 16 herds (6,246 estrous cycles from 3,404 lactations). The equation was tested on a testing data set containing data from 10 herds $(8,105$ estrous cycles from 3,038 lactations). Predictors were selected to be implemented in the final equation if adding them to a base model correcting for timing of insemination and parity decreased the overall likelihood distance of the model. Selected variables (cycle length, milk yield, cycle height, and insemination during the previous estrus) were used to build the final model using a stepwise approach. Predictors were added 1 by 1 in different order, and the model that had the smallest likelihood distance was selected. The final equation included the variables timing of insemination, parity, milk yield, cycle length, cycle height, and insemination during the previous estrus, respectively. The final model was applied to the testing data set and area under the curve (AUC) was calculated. On the testing data set, the final model had an AUC of $58 \%$. When the farm effect was taken into account, the AUC increased to $63 \%$. This equation can be implemented on farms that monitor progesterone and can support the farmer in deciding when to inseminate a cow. This can be the first step in moving the
\end{abstract}

Received December 14, 2016.

Accepted September 1, 2017.

${ }^{1}$ Corresponding author: pierre.blavy@agroparistech.fr focus away from the current paradigm associated with poorer estrus detection, where each detected estrus is automatically inseminated, to near perfect estrus detection, where the question is which estrous cycle is worth inseminating?

Key words: progesterone, probability of insemination success, dairy cow, fertility

\section{INTRODUCTION}

For almost $40 \mathrm{yr}$, progesterone measurements have been used to assess the reproductive status of the cow (Bulman and Lamming, 1978). Interpretation of these progesterone profiles is not always straightforward. Features and shapes may differ according to environmental and cow specific traits, such as feed regimen (Rabiee et al., 2001; Vasconcelos et al., 2003) and milk yield (Wiltbank et al., 2006; Endo et al., 2013). Changes in progesterone concentrations in turn affect the quality of the oocyte and early embryo survival (Carter et al., 2010; Fair and Lonergan, 2012), and thus the overall pregnancy rate.

As the shape and features of progesterone profiles are linked with fertility characteristics that affect pregnancy rate, in theory they could be used to calculate a chance of insemination success for a given estrus in a given cow. To our knowledge, only one published model used progesterone profile features for this purpose (Friggens and Chagunda, 2005; Friggens and Løvendahl, 2008). That model aimed to provide information in real-time to aid decision making about whether or not to inseminate a cow detected in heat. It predicted the chance of future insemination success by looking at the declining slope of progesterone pre-estrus and cycle length of the previous estrous cycle, with chances declining when slope or cycle length move further away from optimal. However, this decrease in chance of insemination success was based on expert opinion and literature, not on actual studies of progesterone profiles. Also, their model did not take into account other factors that have 
been found to be influential in literature, such as milk yield. Studying actual progesterone profiles should improve our knowledge of the effects of profile features and shapes on chance of insemination success. Also, if cow-specific data (e.g., milk yield) can be linked to the profiles, the effects of cow and environmental traits on progesterone profile features can be made visible. Accordingly, the aim of our study was to quantify the effects of progesterone profile features and cow-related factors on insemination success and to provide a realtime predictor equation of probability of insemination success.

\section{MATERIALS AND METHODS}

\section{Data Description}

In our study, progesterone profiles from 26 dairy herds were analyzed to determine actual effects of progesterone slope, cycle length, and cycle height on probability of insemination success. Other factors deemed to be important from literature (e.g., milk yield) were also included to see if they had any effect on probability of insemination success.

Two separate data sets were collected: one for training and one for testing the predictor equation. For the training data set, data were collected over the course of 1 yr (October 2013-November 2014) from 16 dairy herds. For the testing data set, data were collected from 10 other herds between January 2014 and January 2016. All farms were equipped with a Herd Navigator system (Lattec, Hillerød, Denmark). Herd Navigator takes regular milk samples in which, among other measurements, progesterone concentration is determined. Farms were selected based upon the farmers' willingness to provide their data, and were located in the Netherlands $(\mathrm{n}=14)$, Denmark $(\mathrm{n}=3)$, Sweden $(\mathrm{n}$ $=3)$, Canada $(\mathrm{n}=2)$, France $(\mathrm{n}=2)$, and Finland ( $\mathrm{n}$ $=2$ ). Average farm size was 202 cows $($ minimum $=81$, maximum $=371$ ).

\section{Progesterone Sampling}

Progesterone was sampled in milk using the Herd Navigator system. Whenever a cow was eligible for sampling, a milk sample was collected from that milking and sent to the sample intake unit. From there, it was directed to the in-line analyzer, where progesterone concentrations were determined using lateral flow analysis. After determination of progesterone concentration, the model provided feedback to the sampling system on when the next sample for this cow should be taken. To optimize estrus detection, the measurement method was calibrated to be more accurate for low values of progesterone; therefore, values higher than 30 $\mathrm{ng} / \mathrm{mL}$ were replaced by $30 \mathrm{ng} / \mathrm{mL}$.

The sampling window for progesterone in Herd Navigator is 20 to 240 DIM by default. Sampling frequency differs depending on the status of the cow (postpartum anestrus, cyclic, potentially pregnant) and the cycle itself (days from estrus, progesterone slope). The model parameters used to determine sampling frequency are discussed in detail in Friggens and Chagunda (2005). The progesterone profiles in the current study had an average of 1 sample every $2.3 \mathrm{~d}(\mathrm{SD}=0.7)$, and $95 \%$ of the cycles had at least 1 measurement every $7 \mathrm{~d}$.

\section{Estrous Cycle Detection}

Raw progesterone data were used; that is, this study was not conditioned by the Herd Navigator software. For the purpose of characterizing estrous cycles, various points were identified in each progesterone profile (a profile refers to the progesterone trace within a given lactation of a given cow). Any increase in progesterone from $<6$ to $>6 \mathrm{ng} / \mathrm{mL}(\mathbf{X})$ was marked, representing the start of a new luteal phase. The first point where progesterone was $<6 \mathrm{ng} / \mathrm{mL}$ was marked as dropD; the first point where progesterone was $<4 \mathrm{ng} / \mathrm{mL}(\mathbf{O S})$ was also marked (Figure 1). Moving through the lactation, cows were modeled to be in 1 of 3 different stages: unknown, luteal phase, or estrus. At the start of the sampling window or after a gap of $>10 \mathrm{~d}$, cows were in status unknown. When they moved through point X, they were assigned to status luteal phase. When they were in status luteal phase and moved through point OS, they were assigned to status estrus, where they remained until they move through $\mathrm{X}$ again (or if a gap $>10 \mathrm{~d}$ was observed, in which case they were back in status unknown). The first $\mathrm{X}$ in a profile was assumed to indicate the end of the postpartum anestrus period.

These landmarks were used to determine cycle length $\left(\mathrm{OS}_{\mathrm{n}}-\mathrm{OS}_{\mathrm{n}-1}\right)$, estrus to increase $\left(\mathrm{X}_{\mathrm{n}}-\mathrm{OS}_{\mathrm{n}-1}\right)$, and estrus to dropD $\left(\mathrm{OS}_{\mathrm{n}}-\mathrm{dropD}_{\mathrm{n}}\right)$. Cycles longer than $100 \mathrm{~d}$ were assumed to be the result of measurement error and were excluded, as were cycles where the interval estrus to increase exceeded $50 \mathrm{~d}$, cycles where the interval estrus to dropD exceeded $70 \mathrm{~d}$, and cycles where insemination happened $>5$ before or $>10 \mathrm{~d}$ after ovulation.

\section{Insemination and Insemination Success}

Each insemination date was coupled to the closest estrus. As we did not have the timing of insemination available, inseminations were assumed to have occurred at $1200 \mathrm{~h}$. This estimate was based on feedback from 
AI technicians that the majority of inseminations occur between 0800 and $1600 \mathrm{~h}$. For each insemination record, the interval (hours) from estrus to insemination and from insemination to $\mathrm{X}$ was determined.

Each insemination was classified as successful, unsuccessful, or unknown. Inseminations were said to be successful if the median progesterone value in the period 10 to $42 \mathrm{~d}$ postinsemination exceeded $12 \mathrm{ng} / \mathrm{mL}$, and we did not record 2 consecutive progesterone measures below $10 \mathrm{ng} / \mathrm{mL}$ or 1 below $4 \mathrm{ng} / \mathrm{mL}$ in this period.

Given variability between farms and countries in recording protocols, this method was preferred over use of pregnancy determinations, abortions, and calving records. Inseminations that were followed by a gap in the data of at least $10 \mathrm{~d}$ in the first $42 \mathrm{~d}$ were said to be unknown. All other inseminations were classified unsuccessful. Inseminations with unknown status were not used for further analysis. Figure 1 shows 2 examples of a progesterone profile and corresponding inseminations during a lactation.

\section{Available Predictors}

Several potential likelihood of artificial insemination success (LAIS) predictors, which have been suggested in the literature, could be calculated from the progesterone profiles: postpartum anestrus (Darwash et al., 1997a,b; Crowe, 2008), estrus number, estrous cycle length and height (Cerri et al., 2009; Ferraretto et al., 2014; Diaz et al., 2015), upwards slope of progesterone at the start of the estrous cycle, and downward slope of progesterone at the end of the estrous cycle (Blavy et al., 2016). All the estrous cycle measures are for the cycle preceding the estrus for which LAIS is being predicted. Additional information available in this study, deemed relevant from the literature, was milk yield (Sartori et al., 2004; Wiltbank et al., 2006), parity (Hillers et al., 1984; Bagnato and Oltenacu, 1994), calving season (Shahinfar et al., 2014; Hempstalk et al., 2015), DIM (Fenlon et al., 2017), and whether or not there was an insemination to the previous estrus (K.

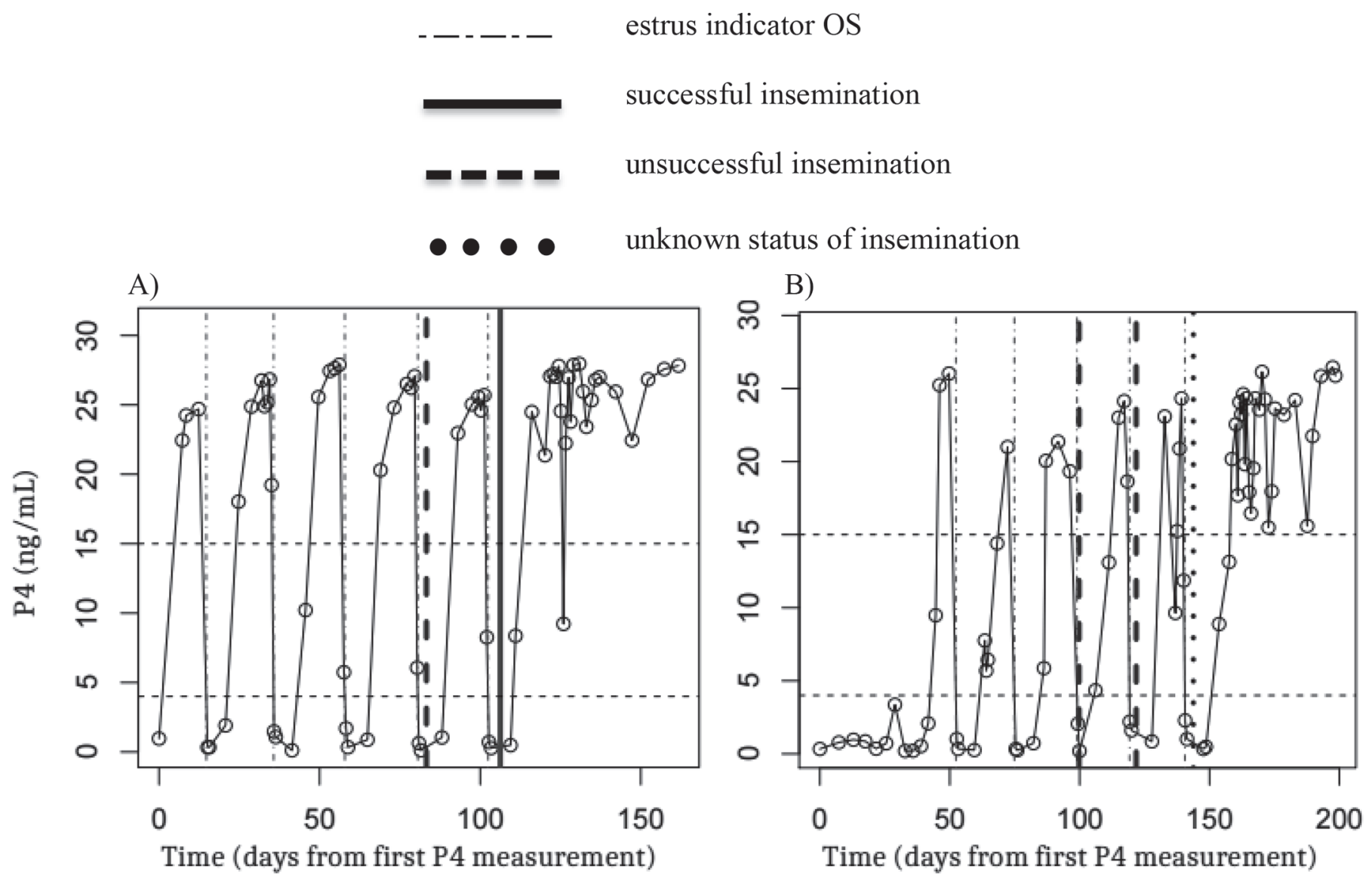

Figure 1. Two examples of progesterone (P4) profiles during lactation. Horizontal dotted lines represent upper (15 ng/mL) and lower (4 ng/ $\mathrm{mL}$ ) $\mathrm{P} 4$ thresholds. OS = first point where P4 was $<4 \mathrm{ng} / \mathrm{mL}$. (A) Regularly cycling cow, with the first 3 estruses not inseminated, the fourth estrus unsuccessfully inseminated, and the fifth estrus successfully inseminated (B) Cow with postpartum anestrus, at the left side of the graph, then 2 estruses that were not inseminated, 2 failed inseminations, and an unknown insemination. 
Nielsen, E. Emanuelson, S. Osteraard, and R. Bage, Lattec, Hillerød, Denmark, personal communication).

The upward slope of the progesterone profile was calculated by fitting a linear model on all data that was collected from -4 to $+2 \mathrm{~d}$ around the point where progesterone first exceeded $15 \mathrm{ng} / \mathrm{mL}$ after the previous estrus. The downward slope of the progesterone profile was calculated by fitting a linear model on the data from $5 \mathrm{~d}$ before cycle end until cycle end. As the Herd Navigator system is calibrated to be most accurate when progesterone concentrations are low, and fewer data points were available when progesterone was high, cycle height was calculated as the median of the highest 5 measurements during each individual cycle. Milk yield was recorded during every visit to the automatic milking system. For use as a predictor, milk yield was calculated as the median of the 10 highest daily milk yield values before that particular OS. Thus, this predictor increased in early lactation up to peak and thereafter represented peak yield in that lactation. Spearman correlation coefficients between variables were calculated; we found no correlations $>|0.5|$ and no variables were discarded based on this correlation matrix. Organizing the data and calculating the potential predictors was done for both the training and testing data set.

The following steps (identifying potential predictors and building the model) were performed on the training data set only. To identify the appropriate functional form of the effect of any potential predictor, the effect of that predictor on insemination success was visualized in 3 steps. In step 1, the relationship between the proportion of insemination success (y-axis) and the variable of interest (x-axis) was plotted. Next, an a priori curve was fitted to the predictor effect shape observed in the visualization plots using the $\mathrm{R}$ Package stats, procedure optim (R Core Team, 2013). Finally, both the predicted data from the a priori curve (yaxis) and the observed data from the data set (x-axis) were plotted to examine differences between observed and predicted values. Final graphs for the appropriate functional forms, together with $P$-values for a HosmerLemeshow test of the residuals of each model, are given in Figure 2.

\section{Formal Model Development}

After visual evaluation of the predictors, the model was built. The accuracy of the model was estimated by computing $\mathrm{LD}=-\log (\mathrm{L})$, where $\mathbf{L D}$ is likelihood distance and $\mathrm{L}$ is the likelihood of the observed data as predicted by the model.

The analysis started with a null model, where LAIS was predicted to be equal to the average observed likelihood of insemination success (i.e., without any explanatory variable; $\mathrm{LD}=2,242.6$ ). This model was first adjusted for time between OS and insemination (LD = $2,230.9$ ) and then for parity ( $\mathrm{LD}=2,205.0)$, resulting in the base model used for selection of potential predictors. Each predictor was added to the model separately. If adding the function to the base model improved the overall LD of the model, it was selected for use in the multivariate model.

Model building was carried out using a stepwise approach, adding the predictors 1 by 1 in different order. The model that had the smallest LD was selected. In the initial model build DIM was not included, as it was considered that the time-related effects on LAIS would be more clearly transduced by the predictor length of postpartum anestrus, estrus number, and milk yield. However, for completion, the inclusion of DIM in the final model was tested.

\section{Testing the Final Model}

The final model was tested on an independent data set (i.e., the above-mentioned testing data set from 10 farms that had not been used in the training data set). To test the appropriateness of each of the chosen predictor variables and that the proposed model is not over-fitted, the LD was computed step by step for the different submodels fitted on the testing data set. The receiver operating characteristic (ROC) curve was plotted and the area under the curve (AUC; the closer to $100 \%$, the better) was computed. Finally, to test for the farm effect, the LAIS_max parameter was a posteriori adjusted per farm and the ROC curve and AUC were calculated including this adjustment for a farm effect. The relationship between predicted and observed values for LAIS in the testing data set was visualized. All statistical analyses were performed with R (R Core Team, 2013).

\section{RESULTS}

\section{General Information on the Data Sets}

The training data set contained 3,404 lactations from 2,641 cows, from which 6,246 complete estrous cycles were extracted. Median cycle length was $23 \mathrm{~d}$. Of all cycles, $56.8 \%$ had an insemination event between -2 to $5 \mathrm{~d}$ after OS. On average, insemination events occurred $2.89 \mathrm{~d}$ after OS, with a standard deviation of $0.77 \mathrm{~d}$.

The testing data set contained 3,038 lactations from 2,845 cows, from which 8,105 complete estrous cycles were extracted. Median cycle length was $23 \mathrm{~d}$. Of all cycles, $59.6 \%$ had an insemination event between -2 to $5 \mathrm{~d}$ after OS. On average, insemination events occurred 


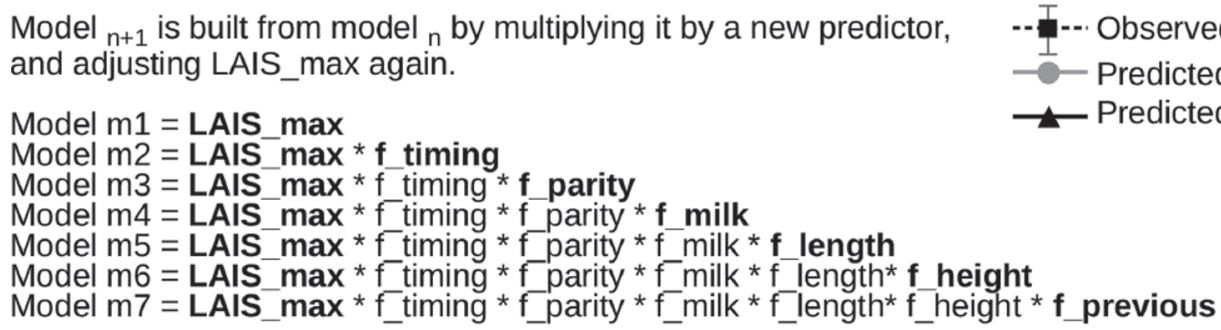

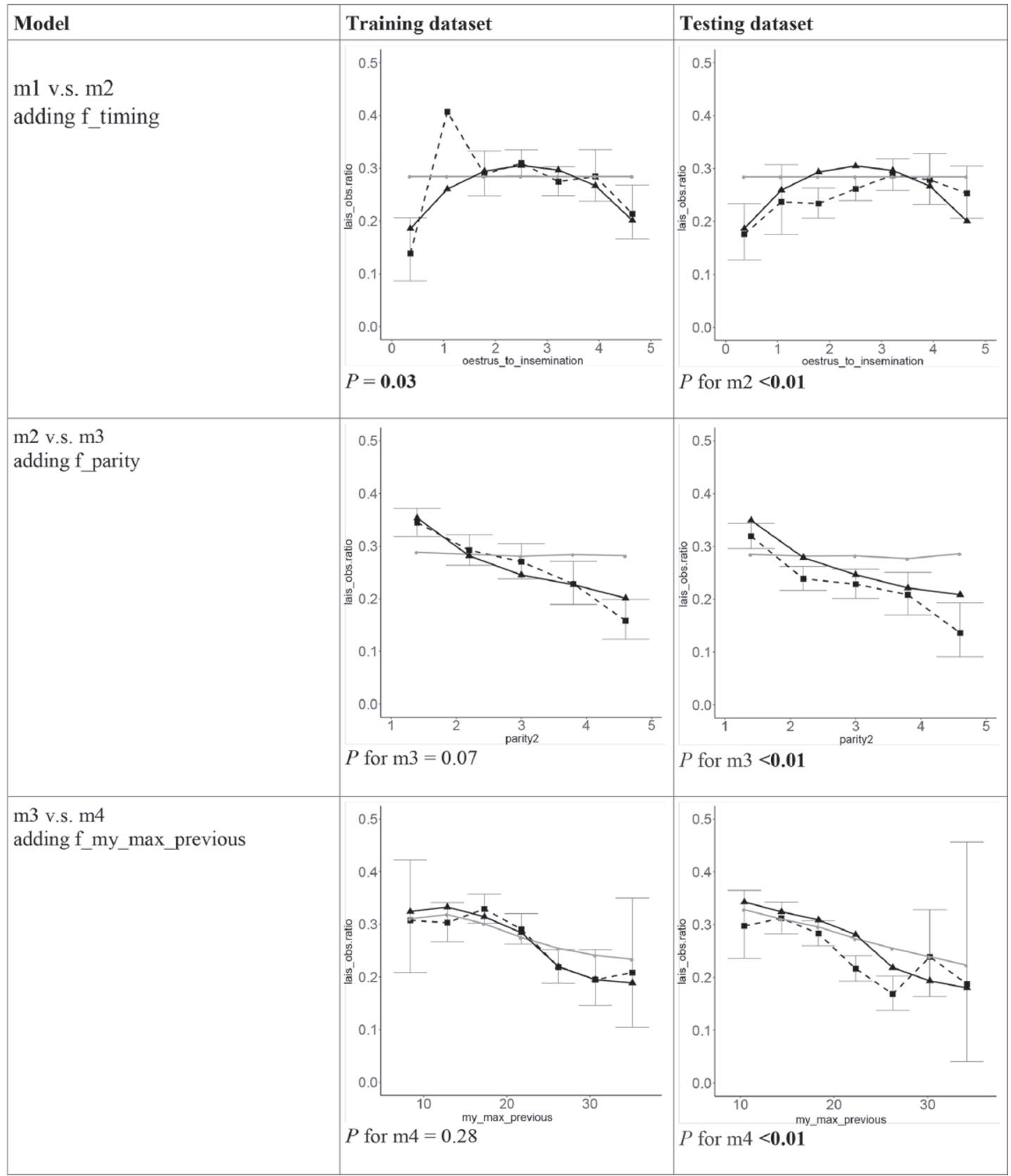

Figure 2. Selection of the appropriate functional form for model predictors. The predicted likelihood of artificial insemination success (LAIS) for each model is shown relative to the model without that predictor (model numbers are the same as in Table 2) and relative to the observed (obs.) LAIS. For the observed LAIS, data were grouped in points to improve the visual aspect of the graph. The vertical lines indicate data dispersion around data points; the length of each line represents the 95\% CI around the mean of each group. The appropriate functional form is displayed for each separate step in the model building process. $P$-values for a Hosmer-Lemeshow test of the residuals are provided below each graph. 
$2.78 \mathrm{~d}$ after OS, with a standard deviation of $0.64 \mathrm{~d}$. Descriptive statistics for progesterone profile features and milk yield are provided in Table 1 .
Frequency distributions of progesterone values, cycle lengths, and the time between 2 consecutive progesterone samples in the training and testing data set were

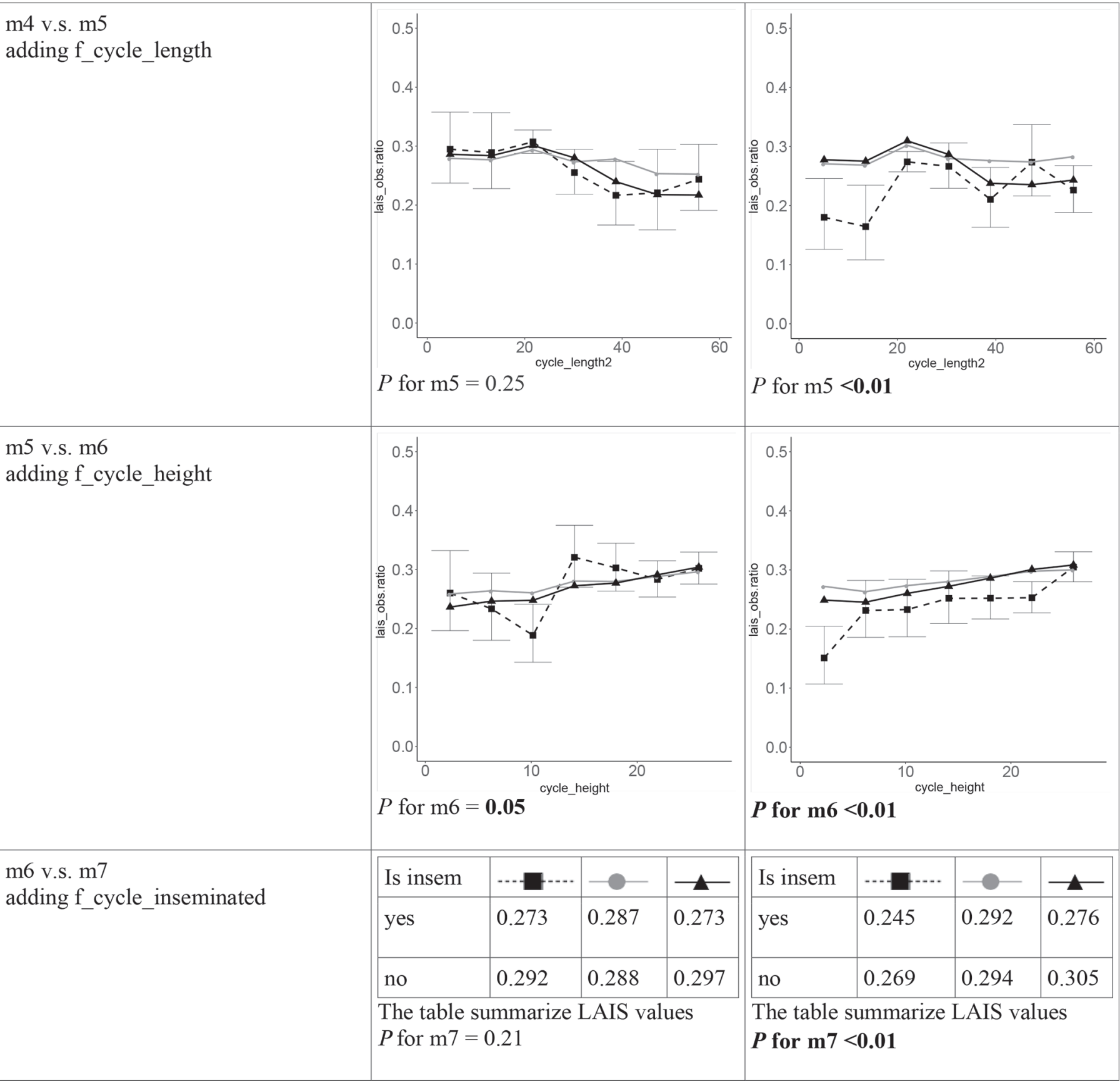

Figure 2 (Continued). Selection of the appropriate functional form for model predictors. The predicted likelihood of artificial insemination success (LAIS) for each model is shown relative to the model without that predictor (model numbers are the same as in Table 2) and relative to the observed (obs.) LAIS. For the observed LAIS, data were grouped in points to improve the visual aspect of the graph. The vertical lines indicate data dispersion around data points; the length of each line represents the $95 \%$ CI around the mean of each group. The appropriate functional form is displayed for each separate step in the model building process. $P$-values for a Hosmer-Lemeshow test of the residuals are provided below each graph. 
Table 1. Mean, median, SD, minimum, and maximum for progesterone profile features and milk yield in the training and testing data set

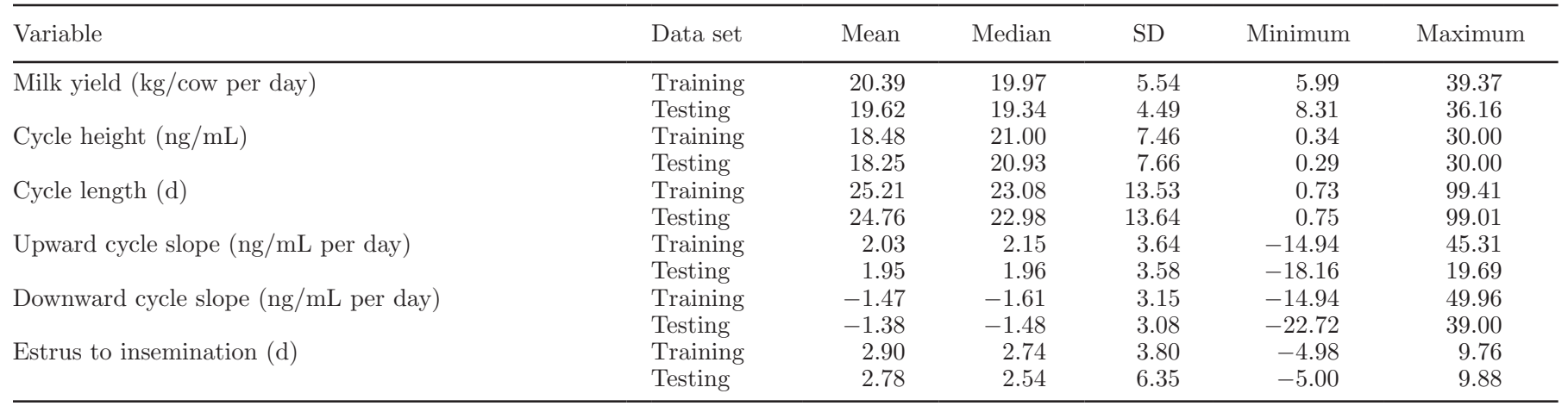

visualized in the same graph, to check for discrepancies in sampling between the 2 data sets. No discrepancies were found.

\section{Selection of Predictors}

The base model had an LD of 2,205.0. The variables cycle length, cycle height, milk yield, and insemination of previous estrus each separately improved base model LD $(2,201.9,2,203.6,2,199.5$, and 2,203.75, respectively), and were therefore kept to build the final model. Adding DIM to the final model did not improve model LD, and replacing milk yield by DIM resulted in a poorer LD.

\section{Formal Model Development}

The selected predictors were added to the base model in different combinations, using a stepwise approach, to find the combination with the smallest distance based on likelihood estimations. Cycle slope was found to increase LD when combined with other predictors, and was therefore removed from the model building process. The final equation is shown in equation 1 :

$$
\begin{aligned}
\text { LAIS }= & \text { LAIS_max } \times \mathrm{f} \_ \text {timing } \times \mathrm{f} \_ \text {parity } \times \mathrm{f} \_ \text {milk } \\
& \times \mathrm{f} \_ \text {length } \times \mathrm{f} \_ \text {height } \times \mathrm{f} \_ \text {previous },
\end{aligned}
$$

where LAIS is likelihood of artificial insemination success; LAIS_max represents the maximum probability of insemination success achievable in the test data set if all circumstances were ideal. The formula contains corrections for timing (f_timing; equation 2) and parity (f_parity; equation 3). It further contains the predictors milk yield (f_milk; equation 4), cycle length of the cycle ending at that estrus (f_length; equation 5), cycle height (f_height; equation 6), and information about insemination of the previous estrus (yes/no; $\mathrm{f}$-previous; equation 7). The separate equations are given below; the coefficients are given in Table 2.

Each new predictor that was added to the model was corrected for the previously added predictors; therefore, the equations are not independent of each other. Equation 2 was calculated as

$\mathrm{f} \_$timing $=$norm[timing_mean, timing_SD,

range(timing, 0,5$)] /$ norm(timing_mean, timing_SD,

$$
\text { timing_mean), }
$$

where $\operatorname{norm}(\mathrm{m}, \mathrm{s}, \mathrm{x})$ is the value at $\mathrm{x}$ of a normal law density function of mean $\mathrm{m}$ and SD s; timing is the estrus to insemination duration in days; timing_mean is the parameter that models the optimum value of time between estrus and insemination; and timing_SD is the parameter that models how strong a deviation from this optimum value affects fertility. The range function is in days (all inseminations are assumed to happen between 0 and $5 \mathrm{~d}$ after OS). Equation 3 was calculated as

$$
\begin{gathered}
\mathrm{f} \_ \text {parity }= \\
\text { parity_b }+(1-\text { parity_b }) / \\
\left(\text { parity }^{\text {parity } \_s}\right),
\end{gathered}
$$

where parity_b is the model parameter that controls the minimum value of the parity function, parity_s is the model parameter that controls the stiffness of the curve, and parity is the number of previous calvings of the cow (1 for primiparous cows, 2 for second parity cows, and so on). Equation 4 was calculated as

$$
\mathrm{f} \_ \text {milk }=\text { range }(\mathrm{x}, 0,1)
$$

$$
\begin{gathered}
\text { with } \mathrm{x}=1-(1-\text { milk_b }) /\{1+\exp [- \text { milk_s } \\
\quad \times(\text { my_max_previous }- \text { milk_i })]\},
\end{gathered}
$$




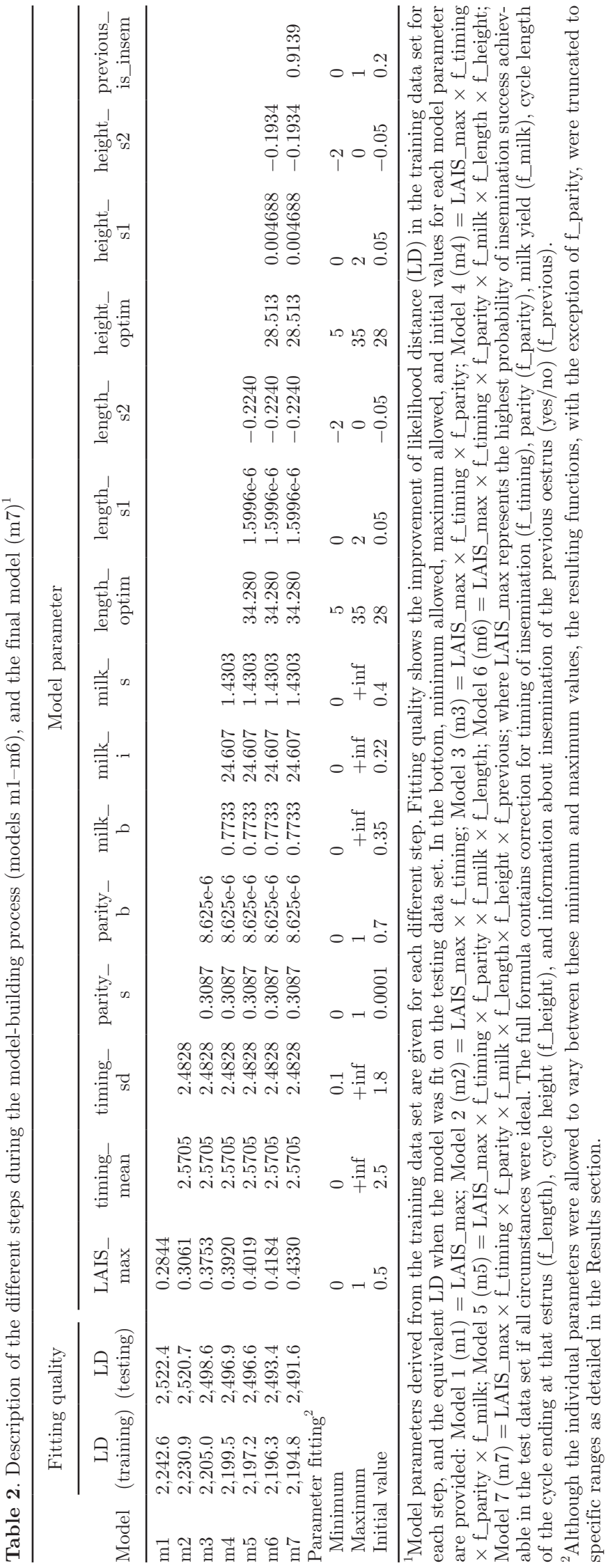

where my_max_previous is the median value of the 10 highest milk yield values before the current insemination date, milk_b is the model parameter that controls the minimum value of this function, milk_i is the model parameter that controls the apsis of the inflection point, and milk_s is the model parameter that control the stiffness of the curve. The effect $\mathrm{f} \_$milk is bounded between 0 and 1 by the range function. Equation 5 was calculated as

$$
\begin{gathered}
\text { f_cycle_length }=\text { range }(\mathrm{x}, 0,1), \\
\text { If cycle_length }<\text { length_optim, } \mathrm{x}=\text { length_s1 } \\
\times \text { range }(15,35, \text { cycle_length }) \\
+(1-\text { length_s1 } \times \text { length_optim }) \text { and } \\
\text { If cycle_length } \geq \text { length_optim, } \mathrm{x}=\text { length_s2 } \\
\quad \times \text { range }(15,35, \text { cycle_length }) \\
+(1-\text { length_s2 } \times \text { length_optim }),
\end{gathered}
$$

where cycle_length is the duration of the previous cycle (from estrus to estrus) in days, length_optim is the model parameter that models the optimum cycle length, length_s1 is the model parameter that models how fertility is affected when the cycle is too short, and length_s2 is the model parameter that models how fertility is affected when the cycle length is either optimal or too long. The effect $\mathrm{f} \_$cycle_length milk is bounded between 0 and 1 by the range function. Equation 6 was calculated as

$$
\mathrm{f} \_ \text {cycle_height }=\text { range }(\mathrm{x}, 0,1) \text {, }
$$

If cycle_height $<$ height_optim, $\mathrm{x}=$ height_s1 $\times$ cycle_height

$+(1$ - height_s1 $\times$ height_optim $)$ and

If cycle_height $\geq$ length_optim, else,

$$
\begin{gathered}
\mathrm{x}=\text { height_s2 } \times \text { cycle_height } \\
+(1-\text { height_s } 2 \times \text { height_optim }),
\end{gathered}
$$

where cycle_height is the median of the 5 highest progesterone values during that cycle, height_optim is the model parameter that models the optimal cycle height, height_s1 is the model parameter that models how fertility is affected when cycle height is below optimal, and height_s2 is the model parameter that models how fertility is affected when the cycle height is above optimal. Equation 7 was calculated as 


$$
\text { f_previous, }
$$

if the previous cycle is inseminated $\mathrm{f}$-previous $=$

$$
\text { previous_is_insem and }
$$

if the previous cycle is not inseminated

$$
\text { f_previous }=1 \text {, }
$$

where previous_is_insem is the parameter that models the effect on fertility when the previous cycle was inseminated.

For each predictor, there is a value where the relation with LAIS is highest. For example, for milk yield, a higher milk yield has a negative effect on AI success (Figure 2). For timing of insemination, the optimum is $2.56 \mathrm{~d}$ after estrus alarm. If inseminations happen $2.56 \mathrm{~d}$ before or after the alarm, this will have a negative influence on LAIS. The equation calculates the distance between the highest value and the actual value for each predictor during the previous cycle, and uses this distance to correct LAIS_max. Model fit including stepwise improvement of LD, together with the values for the model parameters, are shown in Table 2.

\section{Testing the Final Model}

The final model was applied to the testing data set and the ROC curve and AUC were calculated. The ROC curve (i.e., the relationship between true positive rate and false positive rate) is shown in Figure 3. On the testing data set, the final model had an AUC

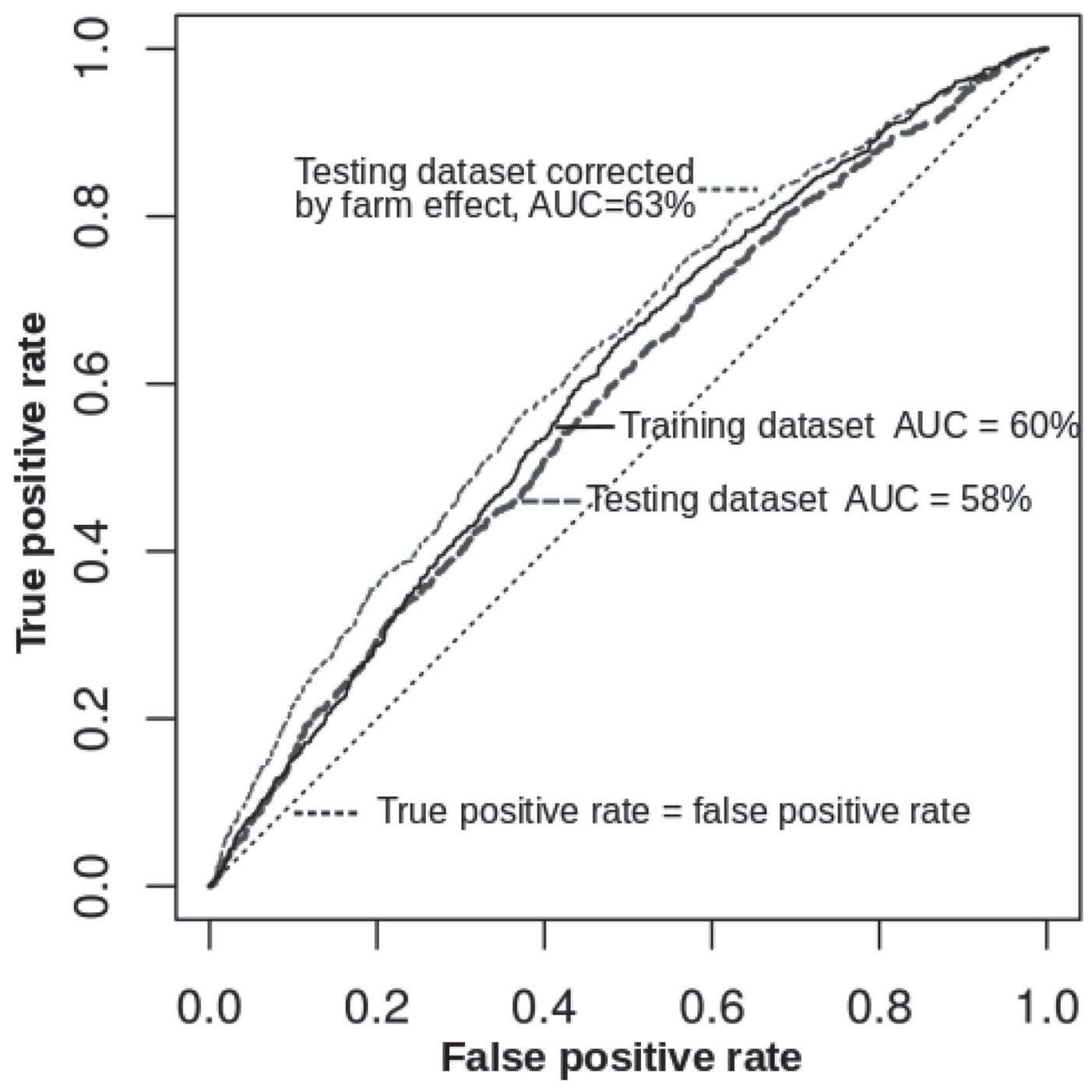

Figure 3. Receiver operating characteristic (ROC) curves for the final model when applied to the testing data set as is or with a correction for a farm effect. For comparison, the ROC curve for the final model applied to the training data set is also shown. AUC = area under the curve. 
of $58 \%$; however, when the farm effect was taken into account the AUC increased to 63\% (Figure 3). Further, fitting the sequence of models in the model building process, but this time on the test data set showed the same sequential improvement in model LD (Table 2). This indicates that the individual predictor variables were valid in the testing data set, which is supported by the visual observation of the observed versus the predicted values, as they are all close to the optimum (Figure 4).

\section{DISCUSSION}

Predictors that were found to improve model LD were cycle length, cycle height, milk yield, and insemination during the previous estrus. Not every step in the model-building process also improved AUC and was significant in a Chi-squared test. Looking at AUC and Chi-squared, equation 4 (including timing of insemination, parity, and milk yield) was the best fitting model. However, the aim of our paper was to develop a model that predicted LAIS the best way possible, with realtime data on farm, the aim was not to find significant relations of potential predictors with LAIS. Therefore, all potential predictors that improved the model based on model LD, even if they were not significant, were retained in the model.

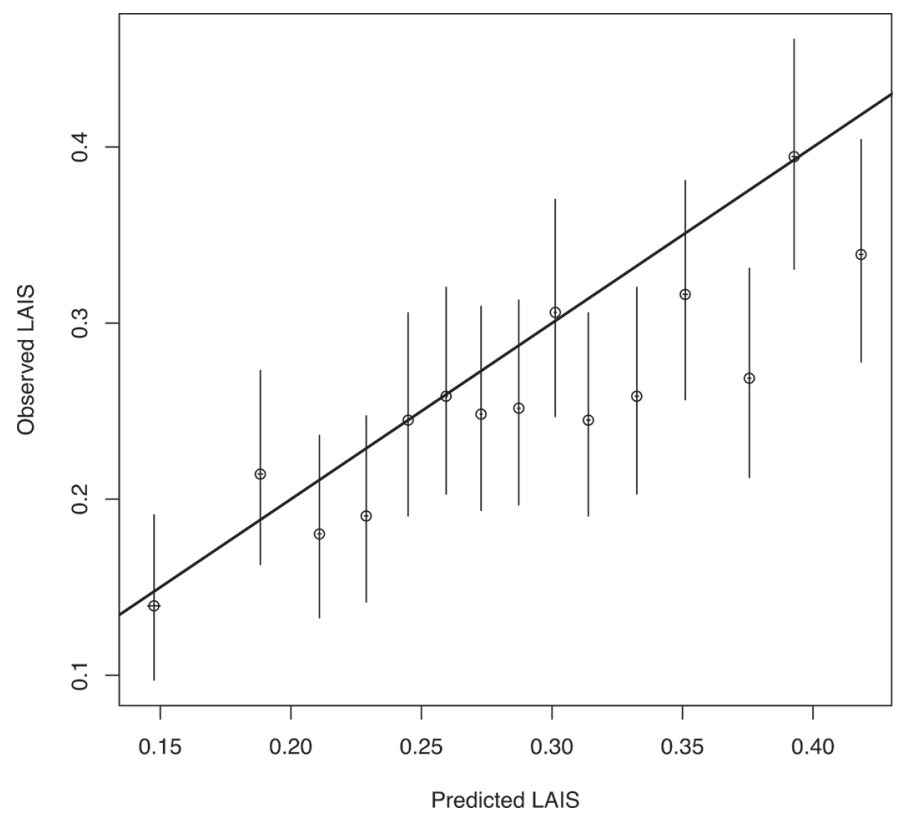

Figure 4. The difference between observed and predicted values for likelihood of artificial insemination success (LAIS) in the testing data set using the final model. Data were grouped in points to improve the visual aspect of the graph. The horizontal and vertical lines indicate data dispersion around data points; the length of each line represents the $95 \%$ CI around the mean of each group.
The final model testing without any adjustment for a farm effect found an AUC value of $58 \%$. This confirmed the ability of the model to predict LAIS on independent data, albeit with a modest prediction accuracy. This can be interpreted as follows: if the model is applied globally, without any farm adjustment, it would be useful to warn the farmer when something is wrong (bad timing, short previous cycle, and so on), but will predict values close to the average insemination success when things go well, which is the case for most inseminations in the data set. When the farm effect was taken into account, the AUC increased to $63 \%$, this suggests that, in the field, as the historical data becomes available, the global farm blind model would improve. Therefore, it seems important for such LAIS prediction systems to be able to adjust to local farm conditions.

Cycle length influences AI success rate (Royal et al., 2000), with optimal cycle length being 18 to 24 $\mathrm{d}$, and shorter and longer cycles representing a decline in AI success. Also, Gorzecka et al. (2011) found that pregnant cows had, on average, shorter follicular phases than nonpregnant cows, indicating a negative effect for longer cycle lengths; those authors did not mention effects of very short cycles on pregnancy rate. The negative relationship between parity and fertility has also been described before (Hillers et al., 1984; Bagnato and Oltenacu, 1994). With respect to cycle height, lower progesterone concentrations (typically $<10 \mathrm{ng} / \mathrm{mL}$ ) are known to negatively affect priming of the uterus for the arrival of the blastocyst, meaning that support of its maintenance and growth by growth factors, nutrients, and steroids is impaired. Impaired growth of the blastocyst increases the chances of it not being able to produce enough IFN- $\tau$ in time to prevent luteolysis, leading to early embryonic death. Low progesterone concentrations on d 5 after ovulation have been related to lower pregnancy rates and impaired embryo development (Mann and Lamming, 2001; Green et al., 2005). In our data set, we found a significant milk yield effect for the optimal timing of insemination. The optimum time of insemination (where LAIS was highest) was 0.35 d later for the $50 \%$ highest-yielding cows than the $50 \%$ lowest-yielding cows. Milk yield has been demonstrated to lower concentrations of progesterone due to higher clearance in the liver (Sartori et al., 2004; Wiltbank et al., 2006). The milk yield effect in our study may support the clearance of progesterone theory: if progesterone is cleared from the bloodstream faster, the curve of progesterone will be flattened. This means that progesterone will reach the threshold of $4 \mathrm{ng} / \mathrm{mL}$ sooner in cows with high clearance rates, leaving more time between estrus detection and actual ovulation. This relationship is important and should be investigated further. It may indicate that, on farms where proges- 
terone measurements are used to determine moment of insemination, inseminating high-yielding cows half a day later may improve LAIS. In our study, cows with higher milk production had lower chance of being pregnant $42 \mathrm{~d}$ postinsemination (Chi-squared, $P<0.01$ ), which may possibly be explained by suboptimal timing.

Variables that were found not to improve LAIS were cycle slope, DIM and estrus number. For cycle slope, this is expected to be due to data density and quality. Herd Navigator is meant to detect estruses; therefore, it takes most samples around the expected time of estrus, or when progesterone is low (for more information on sampling frequency see Friggens and Chagunda, 2005). The system is also calibrated to be most accurate when progesterone concentrations are low. In our data set, this meant we had fewer data points when progesterone was high, with less accurate values. This makes predicting both height and slope subject to noise. For height, this problem was avoided by taking the median of the 5 highest values. This was not possible for slope, as each point contributes to slope separately. Slope is an indicator of the ability of the corpus luteum to secrete progesterone and its subsequent luteolysis. Progesterone concentration during d 0 to 7 postovulation in the previous estrous cycle was found to be important in literature, as low values negatively affect blastocyst development (Carter et al., 2008, 2010; Fair and Lonergan, 2012) and, thus, the overall pregnancy rate. Administration of exogenous progesterone starting between d 1 and 3 postmating was found to positively affect the blastocyst (Garrett et al., 1988; Satterfield et al., 2006; Carter et al., 2010); therefore, slope may be an important predictor for probability of AI success. Still, previous research by Gorzecka et al. (2011), who used a more frequently measured data set, found no differences in estrous cycle shapes between successful and not successful inseminations. More research is needed to determine the separate effects of slope and height of progesterone during the luteal phase on fertility. In contrast to the results of others (Shahinfar et al., 2014; Hempstalk et al., 2015; Rutten et al., 2016; Fenlon et al., 2017), DIM was not found to improve predictive ability of the model in the current study. In the present multisite data set (16 herd training set and 10 herd testing set, from 6 countries) from housed dairy herds, the rise in milk yield of individual animals up to peak was a better predictor of LAIS. Estrus number was also selected as a potential predictor, as a high number of estruses might indicate a lower base fertility for that cow. This relationship was not found in this data set. One reason to explain this might be that the relationship between the cow's metabolic state and infertility is stronger in early ovulations. Therefore, ovulations later in lactation are less influenced by negative energy balance, and thus have a higher probability of being successful. This might overrule the effect of lower base fertility.

Looking at the model fit in Figure 2, some of the outcomes of the Hosmer-Lemeshow test are significant, indicating bias. The Hosmer-Lemeshow test is used to estimate goodness of fit between a model and observed values. The data were split in 10 groups for this test, and significance shows that for at least 1 group predictions may be inaccurate. Looking at the fitting of the training data set, the Hosmer-Lemeshow test for adding cycle height is significant. This could be explained by the fact that cycle height is difficult to estimate correctly, introducing error. For the testing data set, all model steps are significant. This indicates that the model does not perfectly suit new data collected in similar circumstances. Still, fitting the sequence of models in the model-building process showed the same sequential improvement in model LD for the testing data set (Table 2). This indicates that the individual predictor variables were valid in the testing data set, which is supported by the visual observation of the observed versus the predicted values, as they are all close to the optimum (Figure 4).

This database provides an excellent quantification of the effect of time between OS and insemination. For the whole data set combined, the optimum moment of insemination is $2.57 \mathrm{~d}$ after progesterone-based estrus detection. An increase or decrease of $12 \mathrm{~h}$ leads to a relative decrease of AI success of $3.8 \%$. An increase or decrease of $24 \mathrm{~h}$ leads to a relative decrease of AI success of $20.8 \%$. Average time between OS and insemination was $2.83 \mathrm{~d}$ in this data set, with a standard deviation of $0.77 \mathrm{~d}$. However, some uncertainty is attached to these estimates, as most inseminations will have taken place a few hours earlier or later than the assumed time (of $1200 \mathrm{~h}$ ). The methodological approach taken in our study relies on the same criteria, estimating model parameters by minimizing the LD, as do standard methods such as logistic regression and generalized linear model. However, those methods do not directly model probability of successful conception but instead model changes in an odds ratio by applying a link function. In the present study, using the multiplicative models to directly model this probability, we believe it is easier to interpret the predictor and its component functions in biological terms, as described above (see also Figure 2).

In our study, lais_max was found to be $43.3 \%$. Given that lais_max represents the highest predicted likelihood of insemination success (i.e., the cow scores optimal for all significant predictors), this number could be interpreted as meaning that the best conception rate a farmer can hope for is $43 \%$; however, that would be an erroneous interpretation. In the present 
study, the true lais_max is underestimated for reasons of data validation. To be sure of properly classifying insemination outcomes, the following criteria were used: inseminations were said to be successful if the median progesterone value in the period 10 to $42 \mathrm{~d}$ postinsemination exceeded $12 \mathrm{ng} / \mathrm{mL}$ and we did not observe 2 consecutive progesterone measures below 10 $\mathrm{ng} / \mathrm{mL}$ or 1 below $4 \mathrm{ng} / \mathrm{mL}$ in this period. In a large proportion $(21.6 \%)$ of the potentially pregnant cows in this data set, either measurement stopped before 42 d or more than $10 \mathrm{~d}$ elapsed between measurements. These cows were said to be unknown, and therefore not used for further analysis. This likely affected the probability of insemination success negatively, as one important reason to stop measuring prematurely is a manually confirmed pregnancy (K. Nielsen, E. Emanuelson, S. Osteraard, and R. Bage, Lattec, Hillerød, Denmark, personal communication). However, we felt that choosing a shorter time frame $(<42 \mathrm{~d})$ to confirm pregnancy or allowing a larger gap in the data would not have improved the estimations of the model. If the time frame is shortened, cows with long but regular cycles may have been classified as pregnant. If the gap was enlarged, a drop and rise in progesterone could potentially occur during this gap without it showing in the data. This would also classify a regularly cycling cow as pregnant. We believed it was better to allow more cows in status unknown, and calculate the predictions for probability of insemination success with cows that were actually pregnant, than to allow nonpregnant cows to be classified as pregnant and interfere with the quality of the predictions.

\section{CONCLUSIONS}

This paper aimed to determine the effect of progesterone profile features and cow-specific traits on probability of insemination success and to build an equation that can predict likelihood of AI success at the time when estrus is detected. Such an equation can be implemented on farms that monitor progesterone and can support the farmer in deciding when to inseminate an estrus. The final equation included the variables timing of insemination, parity, milk yield, cycle length, cycle height, and insemination during the previous estrus. The predictive ability of the final equation was evaluated on independent testing data set, with and without adjusting for a farm effect. The testing confirmed the validity of the equation and demonstrated an increased predictive ability with inclusion of a farm effect. This equation is the first step in moving the focus away from the current paradigm associated with poorer estrus detection, where each detected estrus is automatically inseminated regardless to the situation of near perfect estrus detection, where the question is which estrus is worth inseminating? These results should be extended by incorporating the effects of important factors that were outside the scope of this study and should, where possible, be validated using reproductive examinations.

\section{ACKNOWLEDGMENTS}

The authors acknowledge the European Union for funding this project. This study was performed as a part of PROLIFIC (KBBE.2012.1.3-04 grant no: 311776).

\section{REFERENCES}

Bagnato, A., and P. A. Oltenacu. 1994. Phenotypic evaluation of fertility traits and their association with milk production of Italian Friesian cattle. J. Dairy Sci. 77:874-882.

Blavy, P., M. Derks, O. Martin, J. K. Höglund, and N. C. Friggens. 2016. Overview of progesterone profiles in dairy cows. Theriogenology 86:1061-1071.

Bulman, D. C., and G. E. Lamming. 1978. Milk progesterone levels in relation to conception, repeat breeding and factors influencing acyclicity in dairy cows. J. Reprod. Fertil. 54:447-458.

Carter, F., N. Forde, P. Duffy, M. Wade, T. Fair, M. A. Crowe, A. C. O. Evans, D. A. Kenny, J. F. Roche, and P. Lonergan. 2008. Effect of increasing progesterone concentration from day 3 of pregnancy on subsequent embryo survival and development in beef heifers. Reprod. Fertil. Dev. 20:368-375.

Carter, F., F. Rings, S. Mamo, M. Holker, A. Kuzmany, U. Besenfelder, V. Havlicek, J. P. Mehta, D. Tesfaye, K. Schellander, and P. Lonergan. 2010. Effect of elevated circulating progesterone concentration on bovine blastocyst development and global transcriptome following endoscopic transfer of in vitro produced embryos to the bovine oviduct. Biol. Reprod. 83:707-719.

Cerri, R. L., H. M. Rutigliano, R. C. Chebel, and J. E. Santos. 2009. Period of dominance of the ovulatory follicle influences embryo quality in lactating dairy cows. Reproduction 137:813-823.

Crowe, M. A. 2008. Resumption of ovarian cyclicity in post-partum beef and dairy cows. Reprod. Domest. Anim. 43:20-28.

Darwash, A. O., G. E. Lamming, and J. A. Wooliams. 1997a. The phenotypic association between the interval to post-partum ovulation and traditional measures of fertility in dairy cattle. Anim. Sci. 65:9-16.

Darwash, A. O., G. E. Lamming, and J. A. Wooliams. 1997b. Estimation of genetic variation in the interval from calving to postpartum ovulation of dairy cows. J. Dairy Sci. 80:1227-1234.

Diaz, P. U., M. L. Stangafero, N. C. Gareis, W. J. Silva, V. Matiller, N. R. Salvetti, F. Rey, F. Barberis, L. Cattaneo, and H. H. Ortega. 2015. Characterization of persistent follicles induced by prolonged treatment with progesterone in dairy cows: An experimental model for the study of ovarian follicular cysts. Theriogenology 84:1149 1160 .

Endo, N., K. Nagai, T. Tanaka, and H. Kamomae. 2013. Changes in plasma progesterone levels in the caudal vena cava and the jugular vein and luteinizing hormone secretion pattern after feeding in lactating and non-lactating dairy cows. J. Reprod. Dev. 59:107-114.

Fair, T., and P. Lonergan. 2012. The role of progesterone in oocyte acquisition of developmental competence. Reprod. Domest. Anim. 47:142-147.

Fenlon, C., L. O'Grady, M. L. Doherty, J. Dunnion, L. Shalloo, and S. T. Butler. 2017. The creation and evaluation of a model predicting the probability of conception in seasonal-calving, pasture-based dairy cows. J. Dairy Sci. 100:5550-5563.

Ferraretto, L. F., H. Gencoglu, K. S. Hackbart, A. B. Nascimento, F. Dalla, R. W. Costa, J. N. Guenther, R. D. Shaver, and M. C. Wiltbank. 2014. Effect of feed restriction on reproductive and metabolic hormones in dairy cows. J. Dairy Sci. 97:754-763. 
Friggens, N. C., and M. G. Chagunda. 2005. Prediction of the reproductive status of cattle on the basis of milk progesterone measures: Model description. Theriogenology 64:155-190.

Friggens, N. C., and P. Løvendahl. 2008. The potential of on-farm fertility profiles: In-line progesterone and activity measurements. Pages 72-78 in Fertility in Dairy Cows: Bridging the Gaps. M. D. Royal, N. C. Friggens. and R. F. Smith, ed. British Society of Animal Science, Cambridge University Press, Cambridge, UK.

Garrett, J. E., R. D. Geisert, M. T. Zavy, and G. L. Morgan. 1988 Evidence for maternal regulation of early conceptus growth and development in beef cattle. J. Reprod. Fertil. 84:437-446.

Gorzecka, J., M. C. Codrea, N. C. Friggens, and H. Callesen. 2011. Progesterone profiles around the time of insemination do not show clear differences between of pregnant and not pregnant dairy cows. Anim. Reprod. Sci. 123:14-22.

Green, M. P., M. G. Hunter, and G. E. Mann. 2005. Relationships between maternal hormone secretion and embryo development on day 5 of pregnancy in dairy cows. Anim. Reprod. Sci. 88:179-189.

Hempstalk, K., S. McParland, and D. P. Berry. 2015. Machine learning algorithms for the prediction of conception success to a given insemination in lactating dairy cows. J. Dairy Sci. 98:5262-5273.

Hillers, J. K., P. L. Senger, R. L. Darlington, and W. N. Fleming. 1984. Effects of production, season, age of cow, days dry, and days in milk on conception to first service in large commercial dairy herds. J. Dairy Sci. 67:861-867.

Mann, G. E., and G. E. Lamming. 2001. Relationship between maternal endocrine environment, early embryo development and inhibition of the luteolytic mechanism in cows. Reproduction 121:175180.

R Core Team. 2013. R: A language and environment for statistical computing. R Foundation for Statistical Computing, Vienna, Austria. http://www.R-project.org/.
Rabiee, A. R., K. L. Macmillan, and F. Schwarzenberger. 2001. The effect of level of feed intake on progesterone clearance rate by measuring faecal progesterone metabolites in grazing dairy cows. Anim. Reprod. Sci. 67:205-214.

Royal, M. D., A. O. Darwash, A. P. F. Flint, R. Webb, J. A. Woolliams, and G. E. Lamming. 2000. Declining fertility in dairy cattle: Changes in traditional and endocrine parameters of fertility. Anim. Sci. 70:487-501.

Rutten, C. J., W. Steenveld, J. C. M. Vernooij, K. Huijps, M. Nielen, and H. Hogeveen. 2016. A prognostic model to predict the success of artificial insemination in dairy cows based on readily available data. J. Dairy Sci. 99:6764-6779.

Sartori, R., J. M. Haughian, R. D. Shaver, G. J. M. Rosa, and M. C. Wiltbank. 2004. Comparison of ovarian function and circulating steroids in estrous cycles of Holstein heifers and lactating cows. J. Dairy Sci. 87:905-920.

Satterfield, M. C., F. W. Bazer, and T. E. Spencer. 2006. Progesterone regulation of preimplantation conceptus growth and galectin 15 (LGALS15) in the ovine uterus. Biol. Reprod. 75:289-296.

Shahinfar, S., D. Page, J. Guenther, V. Cabrera, P. Fricke, and K. Weigel. 2014. Prediction of insemination outcomes in Holstein dairy cattle using alternative machine learning algorithms. J. Dairy Sci. 97:731-742.

Vasconcelos, J. L. M., S. Sangsritavong, S. J. Tsai, and M. C. Wiltbank. 2003. Acute reduction in serum progesterone concentrations after feed intake in dairy cows. Theriogenology 60:795-807.

Wiltbank, M., H. Lopez, R. Sartori, S. Sangsritavong, and A. Gumen. 2006. Changes in reproductive physiology of lactating dairy cows due to elevated steroid metabolism. Theriogenology 65:17-29. 